\title{
Identity Transition and Career Development of Chinese BE Teachers under the Context of BELF
}

\author{
Guo Guihang $^{1} \&$ Li Dan ${ }^{2}$ \\ ${ }^{1}$ School of English for International Business, Guangdong University of Foreign Studies, China \\ ${ }^{2}$ Shenzhen University Normal College Bantian School, China \\ Correspondence: Guo Guihang, School of English for International Business, Guangdong University of Foreign \\ Studies, No.2 Baiyundadaobei, Guangzhou 510420, P.R. China. Tel: 0086-139-2242-3319. E-mail: \\ guihang@gdufs.edu.cn
}

Received: January 21, 2018

Accepted: February 7, $2018 \quad$ Online Published: February 27, 2018

doi:10.5539/hes.v8n2p1

URL: https://doi.org/10.5539/hes.v8n2p1

\begin{abstract}
Business English as a lingua franca (BELF) has aroused increasing research interest in the fields of English for Specific Purposes (ESP) and business communication. In China, Business English as an undergraduate program was approved by the Ministry of Education in 2006 and Business English Studies as a discipline and postgraduate program was initiated in 2008. Under this context, the general English (GE) teachers are facing great challenges of identity change and career development bottlenecks in their transition to the Business English (BE) teachers. This paper discusses the professional qualities required of the BE teachers. Based on the status quo of BE teacher development at Chinese universities, it identifies the key challenges of identity transition and career development bottlenecks of BE teachers. The underlying reasons for transition difficulties and bottlenecks are explored and suggestions are put forth from the post-structural and socio-cultural perspectives.
\end{abstract}

Keywords: BE teachers, identity transition, teacher development, BELF

\section{Introduction}

English as a lingua franca (ELF) is widely used in international business as a common language by business people with different language and cultural background. Business English as a lingua franca or English as a Business lingua franca (BELF) has aroused great research interest in the fields of ELF, ESP, business communication, pragmatics and cross-cultural communication (Charles, 2007; Planken, 2005; Rogersson-Revell, 2010; Bargiela-Chiappini, Nickerson, \& Planken, 2013; Gerritsen \& Nickerson, 2007 ; Kankaanranta, Louhiala-Salminen, Karhunen, 2015; Kankaanranta, \& Louhiala-Salminen, 2013; Nickerson, 2005, 2015; Kankaanranta \& Planken, 2010). In China, since Business English as an undergraduate program was approved by the Ministry of Education in 2006 and Business English Studies as a discipline and postgraduate program was initiated in 2008, researches have emerged on the qualities and competence required of the BE teachers, identity change of GE teachers to BE teachers, and the career development of BE teachers. Due to the lack of BE teachers, most of the 323 universities offering business English undergraduate program require their GE teachers to turn themselves into BE teachers. Inadequate business subject knowledge and business practical experience as well as policy support at the governmental or university level has imposed great challenges on those green-hand $\mathrm{BE}$ teachers in the process of re-positioning themselves and reshaping their professional identity. This paper aims to elucidate the professional qualities and competence required of BE teachers and to explore the key challenges and bottlenecks in BE teachers' identity transition. Based on the elaboration of underlying causes, some suggestions will be put forward to help smoothen the identity transition of green-hand or prospective BE teachers.

\section{Literature Review}

\subsection{Professional Qualities and Competence Required of BE Teachers}

Based on a nation-wide questionnaire survey of BE teachers in China, Guo \& Li (2015) propose a basic framework of professional qualities and competence required of Chinese BE teachers. And this framework can serve as a guideline for BE teachers to readjust themselves. 


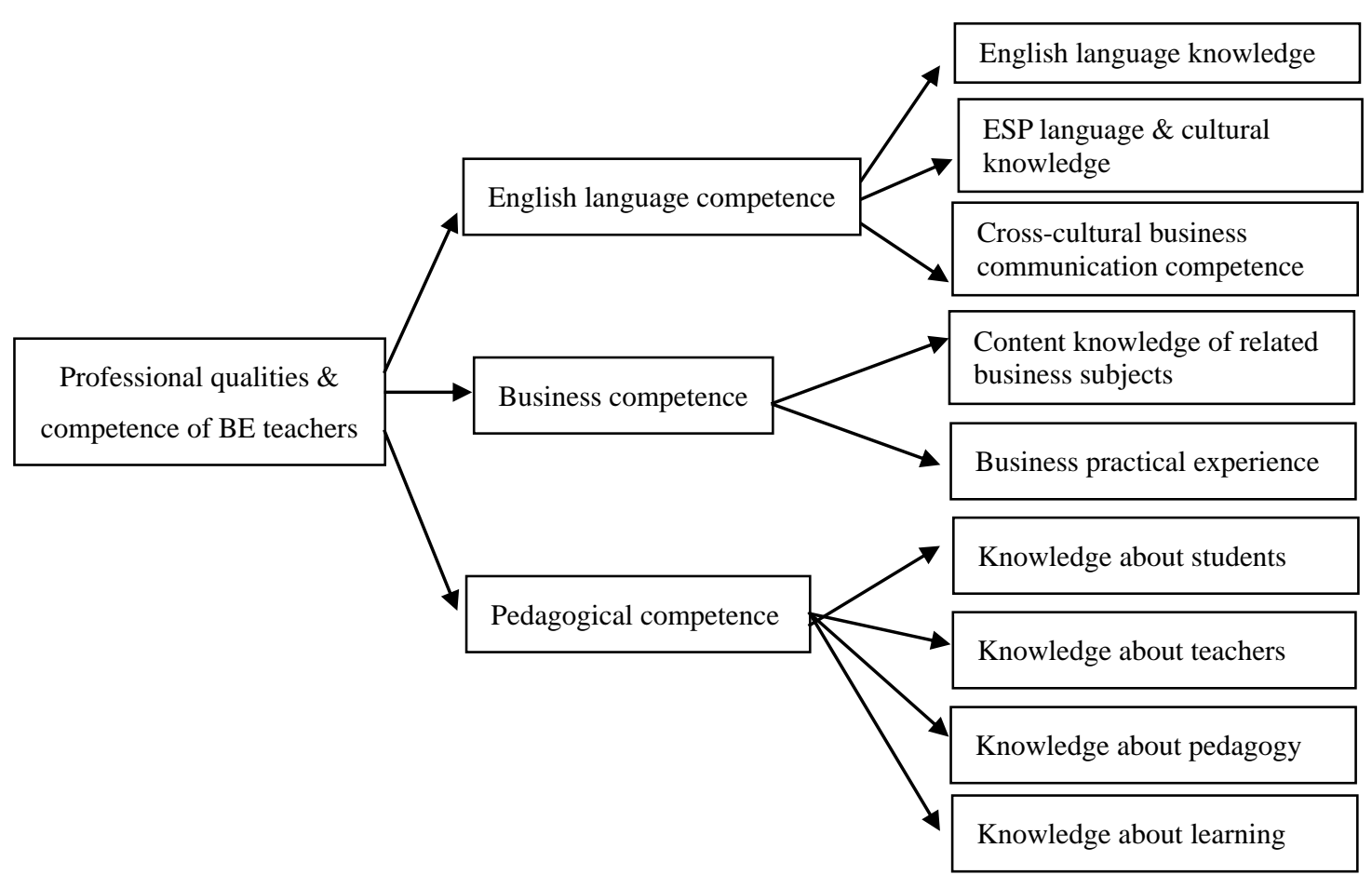

Figure 1. Professional qualities \& competence of BE teachers (adapted from Guo \& Li, 2015, p. 28)

\subsection{Researches on Teacher Identity}

Beijaard, Meijer, \& Verloop (2004) summarize three categories of research on teacher identity, namely, 'teachers' professional identity formation or alteration", "the identification of characteristics of teachers' professional identity", and "studies in which professional identity is (re)presented by teachers' stories" (p. 107). In our research, transition of BE teacher identity is explored, which belongs to the category of "teachers' professional identity formation or alteration".

Some scholars elaborate on the role of social factors in the transformation of teacher identity. Scotland (2014) concludes that the renegotiation of identity is influenced by educational and social context. He studied ten experienced English language teachers who had to alter their pedagogies to meet the educational requirements of a major public institution of higher education in Qatar. The results inferred from the open-ended questionnaires "indicated that the institutionally imposed pedagogical adaptation might result in a renegotiation of professional identity for some teachers" (p. 33). And he also concludes that renegotiation of teacher identity is varied according to individual agency which "mediates interaction between institutional discourses and a teacher's existing identity" (p. 41). Likewise, the "agency" is a key factor in explaining the identity transition of BE teachers since agency plays a part in the process of identity construction and it should be considered when reconciling contradictions and tensions within teachers' professional identities (Day, Kington, Stobart, \& Sammons, 2006).

Hao (2011) demonstrates in her research how Chinese college EFL teacher's identity changes are associated with their academic study toward $\mathrm{PhD}$ degrees. This research indicates that educational context plays a role in teacher identity changes and analyzes characteristics of different teachers' identity. During the process of negotiating personal beliefs and social contexts, it can be noted that "the disciplinary nature of college English teaching has already become a critical factor that affects university EFL teachers' identity and career development"(p. 18). And it cannot be ignored in the research of business English teacher development that business English acts as a discipline with ESP features, and its disciplinary uniqueness requires language teachers to adjust their positions in the context of BE studies and teaching .

Arvaja (2016) explores teacher identity in the context of a one-year programme from the weekly learning diaries written by a university teacher, Anna. According to the narrative analysis, the diaries demonstrate the process of identity construction through Anna's storytelling and narrating. It can be seen that narrative tool can be applied in exploring the process of identity formation. 
In addition, some scholars focus on the role of personal elements in the identity change. Zembylas (2003) employs the narrative tool to discuss the relation between identity and emotion by proposing that "identity transformation occurs when the emotional salience or power of one's experiences changes" (p. 229). He believes "it is important to recognize that teacher identity is constructed across difference that subverts the tradition that conceives identity as a totalizing object of vision" (p. 233). Difference plays a part in the teacher's identity formation. Meanwhile, it is known that business English has become a lingua franca in international business. It is particularly noticeable that in China business English has been offered as an undergraduate and master degree program. Such a change gives rise to difference and change in BE teaching and studies, and transition of BE teacher identity. During the transformation of professional identity, teachers can recognize and deal with their experiences, anxieties, fears, and excitements in effective ways. This provides a mechanism for teachers to negotiate and balance their conflicting emotions.

Cohen (2010) employs dialogical approach to "demonstrate that the teachers made and recognized identity bids to accomplish the professional identity of teacher as learner, using a range of discourse strategies, including two genres of reflective talk" (p. 473). This research also suggests that "professional identity claims often remains implicit" (p. 480). Discourse and talk are related to teachers' psychological activities and also vital to identifying the formation and change of teacher's professional identity.

By reviewing the existing studies on teacher identity, it can be seen that many researches pertain to identity of general language teachers and there is no much elucidation of business English teacher's identity or ESP teacher' identity. However, under the context of BELF, research topics of teacher identity have emerged since difference results in the alteration of teacher's identity (Zembylas, 2003). In China, Business English as an undergraduate program was approved by the Ministry of Education in 2006 and Business English Studies as a discipline and postgraduate program was initiated in 2008. This educational adjustment based on the specific situations and social needs in China requires the transition of Chinese GE teachers to BE teachers. Thereupon, difficulties and challenges are expected in the career development of prospective or would-be BE teachers. Therefore, it is of interest and worthwhile to explore the underlying reasons for the identity transition difficulties of BE teachers. Hopefully, this research will contribute to the BE studies and offer a new perspective to the research on teacher identity.

\section{Theoretical Foundation}

Taylor (2017, p. 17) points out that "early research on teacher identity tended to view the construct of identity as a singular and static one, an approach challenged by more recent research drawing on varied disciplines to frame their explorations of identity". Nowadays, teacher identity is no longer a static matter, and more and more studies explore the change or renegotiation of teacher identity. Arvaja (2016) further elucidates that "both personal and contextual factors shape professional identity negotiations and influence how teachers perceive themselves as professionals" (p. 393). Scholars have elaborated teacher identity from a variety of perspectives. This paper adopts sociocultural and poststructuralist approaches to explore personal and contextual elements of identity transition of BE teachers.

\subsection{Sociocultural Approach to Identity}

Taylor proposes that a sociocultural framework recognizes "identity as an active, ongoing process constructed through social practice" (p. 17). Likewise, teacher identity is not-fixed and can be altered by context.

On one hand, Taylor points out that relations are constructed between identity and activity and claims that identities are shown by language and persons' activities. This viewpoint also does a favor to the research of identity transition of BE teachers. BE teachers' identity renegotiation can be explained from the perspective of teacher practice while teacher identity can in turn influence teacher practice.

On the other hand, "attention must be paid to the role of discourse" (Taylor, p. 17) in the relation between identity and practice, which corresponds with the poststructuralist notion that discourse plays a part in teacher identity. The identity transition of BE teachers has to do with their social interaction. Since business English has become a discipline and an undergraduate degree program in China, BE teachers encounter new teaching circumstances and they shall deal with these changes in social context. Exploring the bottlenecks of BE teachers' career development and identity alteration from the sociocultural perspective can help better understand the constraints on their transition.

\subsection{Poststructuralist Approach to Identity}

Poststructuralist theory "encourages teachers to try to think differently, to ask themselves not only how discourses on emotions and the various norms in their schools have shielded them from their desires, but also 
how it has installed those desires as what they presume themselves to be" (Zembylas, 2003, p.18).

Arvaja (2016) concludes that "multiplicity", "discontinuity" and "sociality" are three major elements of teacher identity from the poststructuralist perspective. He elucidates that teacher identity takes on various characteristics "pertaining to different contexts and relationships" (p. 393). This indicates that teacher identity can be multiple. So the transition of BE teacher identity can be justified by "different dimensions of identity such as professional and personal identity or sub-identities" (p. 393). Since teacher identity is presumed to be unstable, shifting, changing and dynamic, it is reasonable to say that BE teacher identity is changeable. So, the transition of BE teacher identity also demonstrates a discontinuous nature of teacher identity construction. In addition, the social nature of identity from poststructuralist stance corresponds with the sociocultural notion that teacher identity is related to their social interaction. As proposed by Arvaja, social and cultural context including institutional norms, practices, beliefs and discourses are involved in the elaboration and construction of teacher identity. With rapid development of $\mathrm{BE}$ discipline and the fact that 323 universities and colleges have been approved by the Ministry of Education to offer BA programs in Business English, the learners' needs have changed and the social needs for high-quality graduates majoring in Business English impel the traditional GE teachers to reshape their identity to be BE teachers. Such changes in the social context as well as the backdrop of business English becoming a lingua franca in international business require the renegotiation of teacher identity.

Akkerman \& Meijer utilize the theory of dialogical self in psychology to further update the three elements of teacher identity. They suggest "defining teacher identity as an ongoing process of negotiating and interrelating multiple I-positions in such a way that a more or less coherent and consistent sense of self is maintained throughout various participations and self-investments in one's (working) life" (2011, p. 315). They propose three updated features of teacher identity. First, they indicate that the presence of multiple, possibly conflicting I-positions, can be helpful in understanding teacher identity, especially when teachers face dilemmas or tensions throughout their work. Hence, exploring the inner "conflicting I-positions" of BE teachers can help to identify dilemmas facing the BE teachers and to address difficulties in their career development. Secondly, Akkerman \& Meijer note that "discontinuity and continuity" are simultaneously vital in interpreting teacher identity. "Whereas accounting for the discontinuous nature of identity might lead to additional insight into the complexity of teacher identity in relation to their work, at the same time it raises a question of the continuity of identity throughout time" (p. 313). They add "continuity" to demonstrate that identity can be on the shifting process but the inherently patterned behaviors cannot be ignored because a dialogical approach to identity indicates that "continuity" is inherent in the cultural and historical mediation as well as patterned individual behavior. Coincidently, Taylor from sociocultural stance notes identity is continuous and can span contexts and time. "Identities may be constructed in one setting; individuals can carry these identities into new discursive contexts, allowing identity to serve as a resource that travels over space and time" (Taylor, 2017, p. 17). Akkerman \& Meijer also emphasize social and individual features of teacher identity. Being a social participant as well as an autonomous and unique person, teachers can introduce new voices into the communities in which they participate. While the rapid development of business English as a discipline in China can offer opportunities to the BE teachers in developing new I-position by appropriating the educational communities' discourse as their own, the alternative I-positions of BE teachers can also add to the developmental potential of educational communities by means of instilling innovative notions and strategies in BE teaching and research.

\subsection{Dual Perspectives of Research on Teacher Identity}

From the above-mentioned elaboration of teacher identity, it can be seen that sociocultural perspective breathes in the "discourse" of poststructuralist notions, while the poststructuralist approach highlights "the continuous nature" of teacher identity which is also sociocultural viewpoints. As pointed out by Varghese, Morgan, B. Johnston, \& K. Johnson (2005, pp. 37-38), "whereas poststructural theories help us understand teacher identities as constituted through discourse, social theory defines identity as being linked to social context". As such, "multiple theoretical approaches are absolutely essential if we are not to lose sight of the real-world complexity of our subject" (p. 40). Since personal and social factors are intertwined with each other and exert together influence on the transformation of identity of BE teachers and their career development as well, it would be logical and justifiable to combine these two sets of theories to discuss the identity transition and career development of BE teachers in the following parts of this paper.

\section{The Key Challenges of Identity Transition and Career Development Bottlenecks of BE Teachers}

\subsection{Identity Conflict of Double Disciplinary Membership}

Under the context of Business English as a lingua franca, especially with the needs of teaching and doing research in the field of business English, traditional GE teachers may be compelled by the institutions of higher 
education to pursuit a master or PhD degree in business. Hao (2011, p. 16) indicates that teachers "whose $\mathrm{PhD}$ programs were other than the English discipline may suffer from identity conflict of double disciplinary memberships". Likewise, BE teaching and research require teachers to be equipped with language and business knowledge reserve. As a result, some GE teachers pursuing a master or PhD degree in business may doubt their prior professional identity and identity alteration is on the process.

\subsection{Identity Positioning Dilemma of Being a Research-oriented or Teaching-oriented Teacher}

Business English emerged as a new discipline and undergraduate program in China with distinctive features of applied science. In recent years, Chinese government encouraged colleges to turn themselves into application-oriented colleges in order to meet the needs of economic society for applied graduates. Some teachers struggle with their identity positioning of being a research-oriented teacher or teaching-oriented craftsman (Hao, 2011). Some teachers choose to focus on BE teaching in classroom and spare comparatively less time in BE research. This type of teachers are facing bottlenecks in their career development due to the lack of research papers required for academic promotion. In contrast, some teachers may not be adept in BE teaching, but they have achieved research progress in BE field.

\subsection{Lack of Business Practices and Knowledge Reserve}

Business English is a content-based discipline and program. During teacher's transition from GE to BE, difficulty of knowing little about business subjects is found (Guo \& $\mathrm{Li}$, 2015). Teaching business English requires the use of content-based instruction approach, which is demanding for most BE teachers due to the inadequate mastery of subject knowledge and practical business experience.

\subsection{Inadequate English Proficiency for Teaching and Communication}

In China, universities offering Business English programs incorporate some business courses in their curricula and require business teachers to teach subjects fully in English or in a bilingual way. Nevertheless, many business teachers in Chinese universities are not good at teaching in English. English proficiency can be an obstacle during their transition to a BE teacher. Discomfort and frustration may occur to business teachers in the process of renegotiating their identity.

\subsection{Being Unfamiliar with Chinese College Educational Context}

It is argued that BE teachers who hold overseas degrees awarded by English-speaking countries can do better when delivering courses in English. However, while studying abroad for several years, these teachers may not be well informed of domestic policy and educational context. As a result, they also have to experience identity change. As Scotland (2014) suggested, local contexts may require "pedagogical adaptation" and lead to "the renegotiation of the professional identities of English language teachers" (p. 33). Likewise, overseas degree holders may encounter discomfort underpinning different educational contexts during their initial stage of teaching career in Chinese colleges.

\subsection{Lack of Suitable Teaching Methods}

Some business English teachers previously worked in enterprise, so they have gained abundant business experience. However, they don't get the hang of teaching methods and the teaching outcomes may be less productive. Thereupon, adaptation to college context is necessary and the identity change from a business practitioner to an educator ensues.

\section{The Underlying Reasons for Transition Difficulties of BE Teachers}

Currently, the BE teachers at Chinese universities mainly consists of two types of teachers. One is BE teachers transformed from the traditional GE teachers. For this group of teachers, identity conflicts usually result from two juxtaposing disciplines or double disciplinary membership. In their prior teaching career, they were positioned as GE teachers and their teaching activity revolved around GE. Therefore, their professional identity was constructed with the connection to their GE teaching practice. And based on the poststructuralist concepts of "discontinuity and continuity", former identity from GE teaching will span in current BE teaching, while the GE teachers who pursue business degrees will also construct another identity from business learning and teaching activities. These two identities will conflict with each other. As a result, agency mechanism is needed to mediate conflicting identities (Day et al., 2006). So, if GE teachers cannot adjust themselves with a proper agency, problems will occur to their identity transition. Furthermore, the difference between BE and GE gives rises to identity renegotiation. "Identity transformation occurs when the emotional salience or power of one's experiences changes" (Zembylas, 2003, p. 229). Even GE teachers do not switch to teach business courses, they need to understand the differences between GE and BE and change their classroom pedagogy. Hence, 
transitional confusion and obstacles can be expected.

Another group of BE teachers in China consist of teachers who teach business courses. Since most of universities require business teachers to teach business courses fully in English or in a bilingual way, English language proficiency is a key challenge for business teachers. Some may argue that business teachers who got their degrees in English-speaking countries can resolve the deficiency of English language. Yet, lack of knowledge of Chinese educational context and specific economic situations may discourage them when delivering courses back at Chinese universities. From the sociocultural perspective, identity is constructed through teaching activities, and vice versa. Those teachers studying abroad have shaped a teacher identity from their overseas teaching activities that are different from Chinese teaching practice, so they have to adjust their identities based on the Chinese teaching contexts and policies if necessary. Some teachers may become distraught during this identity reshaping process.

\section{Strategies for Facilitating Identity Transition}

To ensure a successful operation of Business English program, we need two kinds of teachers. One is teachers who can teach English language and culture in business context. These teachers are usually transformed from the GE teachers. Another is business teachers. This may be composed of English teachers who obtain a second degree in business and those business teachers who have a good command of English. In either situation, teachers are facing identity alteration due to the change of teaching context. Some suggestions are proposed as follows to help facilitate their identity transition.

\subsection{Formulating Policies at University Level to Support Teachers'Identity Change}

For Business English graduates, English proficiency is still their core competitive advantage in the job market. More important is that they should be able to communicate successfully in business world. As such, BE teachers transformed from GE teachers are actually ESP teachers who are able to teach students to communicate in English across different cultures in the business world. A content-based instruction calls for business knowledge which is key challenge for GE teachers. To help them reshape their identity, if financially feasible, universities can send teachers to study in English-speaking countries. In this way, language teachers can sit in business courses which may help them resolve headaches in subject knowledge when they teach students language knowledge and skills in business context. And business teachers can further improve their ability of conducting courses in English. In case of limited financial resources, universities can hold business lectures regularly according to the subject knowledge input needs of this type of BE teachers. They can choose to attend business teachers' lectures and promptly update their knowledge about regional economic development and heated social and economic issues. Moreover, universities can offer opportunities for these teachers and finance them to attend BE training class or "Open Teaching Week" (an event usually last for several days offering such activities as seminars, class demonstration and observation) organized by other outstanding BE colleges. Training on classroom pedagogy should be provided for BE teachers since the traditional GE teaching methods may not fit the BE teaching context. Such teaching methods as case study, heuristic teaching, flipped classroom or inquiry learning, reflective learning should be encouraged. To facilitate the identity transition, we can establish teacher-teams "as forums for creating emotional and professional bonding" (Zembylas, 2003, p. 230).

Some English teachers may choose to transform themselves into business teachers. Such a great leap in identity requires them to obtain a second degree in business, do research and publish academic papers in the field of business disciplines in order to achieve academic promotion. And they should compete with other peers to get academic promotion in Business discipline. This requires university-level policy to allow these teachers to apply for professorship if their research and academic attainments meet the qualifications in the related business discipline. A mentoring system is also important to alleviate tension and pressure of transformation. Zembylas (2003) sheds light on "a poststructuralist account of emotions and teacher identity brings to teachers' attention the relationship between emotion, identity and power, and moves teachers to engage in self-transformation through a richer understanding of their situatedness" (p. 229). So, perseverance and emotional mentoring are vital for the transformed business teachers.

\subsection{Relocating Research Fields for BE Teachers after Their Identity Transformation}

With the alteration of identity, BE teachers may have to relocate their research fields. Language teachers may find it difficult to adapt themselves to the research in the field of business linguistics, while business teachers transformed from GE teachers may find it hard to start with their research in the business fields. Empirical research based on modeling is a hard nut to crash for business teachers transformed from GE teachers. Training should be offered to BE teachers on research methods and the ability of using statistical analysis. Research teams may be established to help green-hand or would-be BE teachers to identify possible research areas. For example, 
language teachers may be redirected to the research in business linguistics such as research on business terminology, compilation of bilingual business dictionary, business discourse analysis, business text analysis, business genre analysis, corpus-based business language analysis, multi-modal business discourse analysis, business translation, etc. Their research interest may be expanded to such fields as business communication, studies on business/corporate/industry culture, business ethics, and corporate social responsibility. Research on business English education can be explored, including corpus-based textbook evaluation and development of BE teaching materials, curriculum design, modes of BE talents training, ESP pedagogy, and business English testing. Business teachers transformed from GE teachers may start with their research with familiar topics related to their prior identity as a teacher teaching English language and culture. Their prior research experience in linguistics and culture may offer them distinctive perspectives of business studies, such as exploring the cultural influence of Chinese accounting reform, studies on national business culture and policies of countries alongside the "one belt, one road" proposed by the Chinese government, and studies on the adaption of foreign-invested enterprises or foreign business people to the local culture in China. Participation in such professional association as CIMA, ACCA, CMA and QP can provide latest industry developments for the BE teachers, from which research topics may be identified.

\subsection{Improving BE Teachers' Business Experience and Skills through a University-enterprise Cooperation Mechanism}

Business English is an application-oriented undergraduate program in China, a mere instillation of theories in class cannot achieve desired effects of education. BE teachers, especially business teachers, should equip themselves with business experience and skills. Even for BE teachers who teach business linguistics and culture, the industry experience and business skills may help improve teaching effectiveness in such class involving business meetings, business reports, business presentation and entertainment. Cooperating with business enterprises is to make good use of different educational environment and resources to polish students' business skills and employability. By taking advantage of alumni resources, BE teachers can take a temporary post in the business enterprises to accumulate industrial experience, which in return, may help mentor the students.

\section{Conclusion}

Business English is a new undergraduate program and emerging discipline in China. BE teachers, whether they used to be GE teachers, business teachers or business practitioners, need to reshape or alter their identity in order to adapt themselves to the new teaching and research context. Besides the personal efforts needed for the institutionally imposed pedagogical adaptation, university authorities also need to formulate policies to motivate and facilitate the renegotiation of professional identities of BE teachers and help them develop new I-positions so that the alternative I-positions of BE teachers can add to the developmental potential of educational communities by means of instilling innovative notions and strategies in BE teaching and research.

\section{Acknowledgements}

This research was supported with funds from South China Business College of Guangdong University of Foreign Studies under the provincial research project of the Improvement of the Professional and Pedagogical Abilities of Business English Teachers, and the university-level research project of the Career Development Strategies for the Business English Teachers of Guangdong University of Foreign Studies. The support is gratefully acknowledged.

\section{References}

Akkerman, S., \& Meijer P. (2011). A dialogical approach to conceptualizing teacher identity. Teaching and Teacher Education, 27, 308-319. https://doi.org/10.1016/j.tate.2010.08.013

Arvaja, M. (2016). Building teacher identity through the process of positioning Teaching and Teacher Education, 59, 392-402. https://doi.org/10.1016/j.tate.2016.07.024

Bargiela-Chiappini, F., Nickerson, C., \& Planken, B. (2013). Business Discourse, Basingstoke: Palgrave Macmillan. https://doi.org/10.1057/9781137024930

Beijaard, D., Meijer, P., \& Verloop, N. (2004). Reconsidering research on teachers' professional identity. Teaching and Teacher Education, 20, 107-128. https://doi.org/10.1016/j.tate.2003.07.001

Charles, M. (2007). Language matters in global communication. Journal of Business Communication, 3, 260-282. https://doi.org/10.1177/0021943607302477

Cohen, J. (2010). Getting recognised: Teachers negotiating professional identities as learners through talk. Teaching and Teacher Education, 26, 473-481. https://doi.org/10.1016/j.tate.2009.06.005 
Day, C., Kington, A., Stobart, G., \& Sammons, P. (2006). The personal and professional selves of teachers: stable and unstable identities. British Educational Research Journal, 32(4), 601-616. https://doi.org/10.1080/01411920600775316

Gerritsen, M., \& Nickerson, C. (2009). BELF: Business English as a lingua franca. In F. Bargiela-Chiappini (ed.), The Handbook of Business Discourse. Edinburgh, Scotland: Edinburgh University Press, 180-192.

Guo, G. H., \& Li, D. (2015). Business English Teachers' Professional Qualities and Development Based on ESP Demand Theory. Journal of PLA University of Foreign Languages, 5, 26-32.

Hao, C. H. (2011). Changes and Characteristics of EFL Teachers' Professional Identity: The Cases of Nine University Teachers. Chinese Journal of Applied Linguistics (Quarterly), 1, 3-21. https://doi.org/10.1515/cjal.2011.001

Kankaanranta, A., \& Louhiala-Salminen, L. (2013). What language does global business speak? - The concept and development of BELF. Ibérica, the Journal of the European Association of Languages for Specific Purposes, 26, 17-34.

Kankaanranta, A., \& Planken, B. (2010). BELF competence as business knowledge of internationally operating business professionals. Journal of Business Communication, 47(4), 380-407. https://doi.org/10.1177/0021943610377301

Kankaanranta, A., Louhiala-Salminen, L., \& Karhunen, P. (2015). English in multinational companies: implications for teaching "English" at an international business school. Journal of English as a Lingua Franca, 4(1), 125-148. https://doi.org/10.1515/jelf-2015-0010

Nickerson, C. (2005). English as a lingua franca in international business contexts. English forSpecific Purposes, 24, 367-380. http://dx.doi.org/10.1016/j.esp.2005.02.001

Nickerson, C. (2015). The death of the non-native speaker? English as a lingua franca in business communication: A research agenda. Language Teaching, 48(3), 390-404. https://doi.org/10.1017/S0261444815000129

Planken, B. (2005). Managing rapport in lingua franca sales negotiations: A comparison of professional and aspiring negotiators. English for Specific Purposes, 24(4), 381-400. http://dx.doi.org/10.1016/j.esp.2005.02.002

Rogerson-Revell, P. (2010). "Can you spell that for us nonnative speakers?": Accommodation strategies in international business meetings. Journal of Business Communication, 47(4), 432-454. https://doi.org/10.1177/0021943610377304

Scotland, J. (2014). Operating in global educational contact zones: How pedagogical adaptation to local contexts may result in the renegotiation of the professional identities of English language teachers. Teaching and Teacher Education, 37(1), 33-43. https://doi.org/10.1016/j.tate.2013.09.002

Taylor, L. (2017). How teachers become teacher researchers: Narrative as a tool for teacher identity construction. Teaching and Teacher Education, 61, 16-25. http://dx.doi.org/10.1016/j.tate.2016.09.008

Varghese, M., Morgan, B., Johnston, B., \& Johnson, K. (2005). Theorizing Language Teacher Identity: Three Perspectives and Beyond. Journal of Language, Identity \& Education, 4, 21-44. https://doi.org/10.1207/s15327701jlie0401_2

Zembylas, M. (2003). Emotions and Teacher Identity: A poststructural perspective. Teachers and Teaching: theory and practice, 9(3), 213-238. https://doi.org/10.1080/13540600309378

\section{Copyrights}

Copyright for this article is retained by the author(s), with first publication rights granted to the journal.

This is an open-access article distributed under the terms and conditions of the Creative Commons Attribution license (http://creativecommons.org/licenses/by/4.0/). 